NASA/TM-2009-215668

AIAA-2009-1876

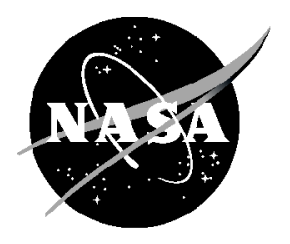

\title{
The Case for Intelligent Propulsion Control for Fast Engine Response
}

Jonathan S. Litt

Glenn Research Center, Cleveland, Ohio

Dean K. Frederick

Saratoga Control Systems, Inc., Saratoga Springs, New York

Ten-Huei Guo

Glenn Research Center, Cleveland, Ohio 


\section{NASA STI Program . . . in Profile}

Since its founding, NASA has been dedicated to the advancement of aeronautics and space science. The NASA Scientific and Technical Information (STI) program plays a key part in helping NASA maintain this important role.

The NASA STI Program operates under the auspices of the Agency Chief Information Officer. It collects, organizes, provides for archiving, and disseminates NASA's STI. The NASA STI program provides access to the NASA Aeronautics and Space Database and its public interface, the NASA Technical Reports Server, thus providing one of the largest collections of aeronautical and space science STI in the world. Results are published in both non-NASA channels and by NASA in the NASA STI Report Series, which includes the following report types:

- TECHNICAL PUBLICATION. Reports of completed research or a major significant phase of research that present the results of NASA programs and include extensive data or theoretical analysis. Includes compilations of significant scientific and technical data and information deemed to be of continuing reference value. NASA counterpart of peer-reviewed formal professional papers but has less stringent limitations on manuscript length and extent of graphic presentations.

- TECHNICAL MEMORANDUM. Scientific and technical findings that are preliminary or of specialized interest, e.g., quick release reports, working papers, and bibliographies that contain minimal annotation. Does not contain extensive analysis.

- CONTRACTOR REPORT. Scientific and technical findings by NASA-sponsored contractors and grantees.
- CONFERENCE PUBLICATION. Collected papers from scientific and technical conferences, symposia, seminars, or other meetings sponsored or cosponsored by NASA.

- SPECIAL PUBLICATION. Scientific, technical, or historical information from NASA programs, projects, and missions, often concerned with subjects having substantial public interest.

- TECHNICAL TRANSLATION. Englishlanguage translations of foreign scientific and technical material pertinent to NASA's mission.

Specialized services also include creating custom thesauri, building customized databases, organizing and publishing research results.

For more information about the NASA STI program, see the following:

- Access the NASA STI program home page at http://www.sti.nasa.gov

- E-mail your question via the Internet to help@ sti.nasa.gov

- Fax your question to the NASA STI Help Desk at $443-757-5803$

- Telephone the NASA STI Help Desk at 443-757-5802

- Write to: NASA Center for AeroSpace Information (CASI) 7115 Standard Drive Hanover, MD 21076-1320 
NASA/TM-2009-215668

AIAA-2009-1876

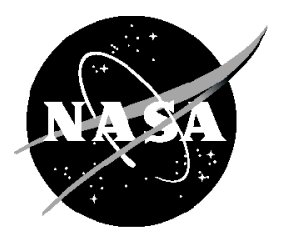

\section{The Case for Intelligent Propulsion Control for Fast Engine Response}

Jonathan S. Litt

Glenn Research Center, Cleveland, Ohio

Dean $K$. Frederick

Saratoga Control Systems, Inc., Saratoga Springs, New York

Ten-Huei Guo

Glenn Research Center, Cleveland, Ohio

Prepared for the

Infotech@Aerospace Conference

sponsored by the American Institute of Aeronautics and Astronautics

Seattle, Washington, April 6-9, 2009

National Aeronautics and

Space Administration

Glenn Research Center

Cleveland, Ohio 44135 


\section{Acknowledgments}

The authors wish to acknowledge Shreeder Adibhatla of General Electric Aircraft Engines for many informative discussions on engine control, N\&R Engineering, Inc., for facilitating the controller development, and the NASA Aviation Safety Program Integrated Resilient Aircraft Control Project for funding this work.

Level of Review: This material has been technically reviewed by technical management.

Available from

NASA Center for Aerospace Information

7115 Standard Drive

Hanover, MD 21076-1320
National Technical Information Service 5285 Port Royal Road Springfield, VA 22161

Available electronically at http://gltrs.grc.nasa.gov 


\title{
The Case for Intelligent Propulsion Control for Fast Engine Response
}

\author{
Jonathan S. Litt \\ National Aeronautics and Space Administration \\ Glenn Research Center \\ Cleveland, Ohio 44135 \\ Dean K. Frederick \\ Saratoga Control Systems, Inc. \\ Saratoga Springs, New York 12866 \\ Ten-Huei Guo \\ National Aeronautics and Space Administration \\ Glenn Research Center \\ Cleveland, Ohio 44135
}

\begin{abstract}
Damaged aircraft have occasionally had to rely solely on thrust to maneuver as a consequence of losing hydraulic power needed to operate flight control surfaces. The lack of successful landings in these cases inspired research into more effective methods of utilizing propulsion-only control. That research demonstrated that one of the major contributors to the difficulty in landing is the slow response of the engines as compared to using traditional flight control. To address this, research is being conducted into ways of making the engine more responsive under emergency conditions. This can be achieved by relaxing controller limits, adjusting schedules, and/or redesigning the regulators to increase bandwidth. Any of these methods can enable faster response at the potential expense of engine life and increased likelihood of stall. However, an example sensitivity analysis revealed a complex interaction of the limits and the difficulty in predicting the way to achieve the fastest response. The sensitivity analysis was performed on a realistic engine model, and demonstrated that significantly faster engine response can be achieved compared to standard Bill of Material control. However, the example indicates the need for an intelligent approach to controller limit adjustment in order for the potential to be fulfilled.
\end{abstract}

\section{Nomenclature}

$\begin{array}{ll}\text { BOM } & \text { Bill of Material } \\ \text { C-MAPSS } & \begin{array}{l}\text { Commercial Modular Aero-Propulsion System Simulation } \\ \text { engine pressure ratio }\end{array} \\ \text { EPR } & \text { Federal Aviation Administration } \\ \text { FAA } & \text { Full Authority Digital Engine Control } \\ \text { FADEC } & \text { high pressure compressor } \\ \text { HPC } & \text { Integrated Resilient Aircraft Control } \\ \text { IRAC } & \text { regulator for variable } x \\ \text { K }_{x}(\mathrm{~s}) & \text { low cycle fatigue } \\ \text { LCF } & \text { low pressure compressor } \\ \text { LPC } & \text { low pressure shaft speed (fan speed) } \\ N 1 & \text { high pressure shaft speed (core speed) } \\ N 2 & \text { engine acceleration control mode } \\ \text { NDOT } & \text { compressor exit static pressure } \\ P S 3 & \text { radians per second } \\ \text { rps } & \text { sea level static } \\ \text { SLS } & \text { high pressure turbine outlet temperature } \\ T 48 & \text { throttle resolver angle } \\ \text { TRA } & \text { fuel flow } \\ W f & \text { WflPS3 } \\ \Phi & \end{array}$




\section{Introduction}

In the Sioux City accident, the center, tail-mounted engine of a United Airlines DC-10 suffered an uncontained failure in flight, that resulted in the loss of all hydraulic systems as well as airframe damage. Using thrust from the two remaining engines alone to maneuver, the crew was able to fly the crippled aircraft to the Sioux City, Iowa, airport, where they successfully crash landed (Ref. 1). As a result, research was conducted to investigate and improve the pilot's ability to land an airplane using propulsion-only control (Ref. 2). Studies showed that differential thrust generated by the propulsion system could be used to maneuver the vehicle, but landing was extremely difficult because of the relatively slow response of the engine compared to traditional flight control (Refs. 3 and 4). In fact, it was reported (Ref. 4) that the response of the B-727 Commercial Jet Transport's low-bypass JT8D turbofan engines was slow $(3 \mathrm{sec})$ from idle to a low power setting, then fast $(3 \mathrm{sec})$ to reach full thrust. Slow engine response at low power settings was also observed on the B-747's PW4056 engines and the C-17 Military Jet Transport's F117 engines. It was noted that it is important to have engine thrust well above idle for faster engine response and thrust modulation. It was further noted that small throttle pulses may be more effective than larger throttle movements.

The Federal Aviation Administration (FAA) has set a requirement for the response time of an engine, FAA Federal Aviation Regulation Section 33.73 - Power or thrust response:

The design and construction of the engine must enable an increase

(a) From minimum to rated takeoff power or thrust with the maximum bleed air and power extraction to be permitted in an aircraft, without overtemperature, surge, stall, or other detrimental factors occurring to the engine whenever the power control lever is moved from the minimum to the maximum position in not more than $1 \mathrm{sec}$, except that the Administrator may allow additional time increments for different regimes of control operation requiring control scheduling; and

(b) From the fixed minimum flight idle power lever position when provided, or if not provided, from not more than 15 percent of the rated takeoff power or thrust available to 95 percent rated takeoff power or thrust in not over $5 \mathrm{sec}$. The 5 -sec power or thrust response must occur from a stabilized static condition using only the bleed air and accessories loads necessary to run the engine. This takeoff rating is specified by the applicant and need not include thrust augmentation.

This requirement sets a maximum delay and rise time (loosely defined) that must be met by all commercial turbofan engines, and it is not unreasonable to expect that the response of some engines, especially large ones, will not be much faster than this. It is important to note that part (b) requires the 5 -sec transient to begin at 15 percent of takeoff power, which is high enough to cut out the most sluggish early part of the response, such as that mentioned for the JT8D.

Fast thrust response is especially important when the pilot is attempting to use the engines as flight control effectors. This is not the normal use of engines, since their reaction time is much slower than that of traditional flight control surfaces. A pilot can observe changes in the plane's attitude almost immediately using normal flight control, and the control surfaces have a lot of authority, i.e., they cause the yaw, pitch, and roll rates to be much higher than the engines alone can, and the authority of the engines depends on the aircraft configuration. If the engines could deliver higher than normal thrust, it would have the potential to improve attitude control because the control authority would be increased.

Delivery of excess thrust, i.e., thrust beyond the normal maximum, might also be required in situations involving airframe damage or shorter than normal takeoff distance. In-flight airframe damage might be caused by a mid-air collision or structural fatigue (Ref. 5). Loss of a portion of a wing might require excess thrust to maintain lift. Shorter than normal takeoffs might be the result of a runway incursion (Ref. 6) or accidental use of a runway that is too short (Ref. 7).

The Integrated Resilient Aircraft Control (IRAC) project of the NASA Aviation Safety Program seeks to investigate propulsion-assisted flight control by finding ways to improve the responsiveness of the engines as well as ways to provide excess thrust (Ref. 8). While the objective is to control thrust, measured variables such as fan speed (NI) or Engine Pressure Ratio (EPR), which are indicative of thrust, are typically controlled, since thrust is not measurable in flight. The overthrust and fast engine response scenarios are both shown in Figure 1. The figure shows example situations, the type of engine response required, and the negative impacts of the required response on the engine. The bottom left of the figure shows temperature and speed curves exceeding normal structural limits (represented by the horizontal lines on the plot) in order to achieve overthrust operation. The bottom right shows a 


\section{Requirements via Scenario Analysis Using Aircraft Flight Simulator}

\section{(1) Takeoff Incursion}

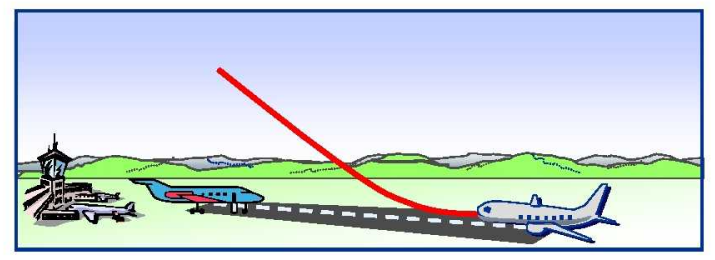

Requiring Additional

\section{Thrust}

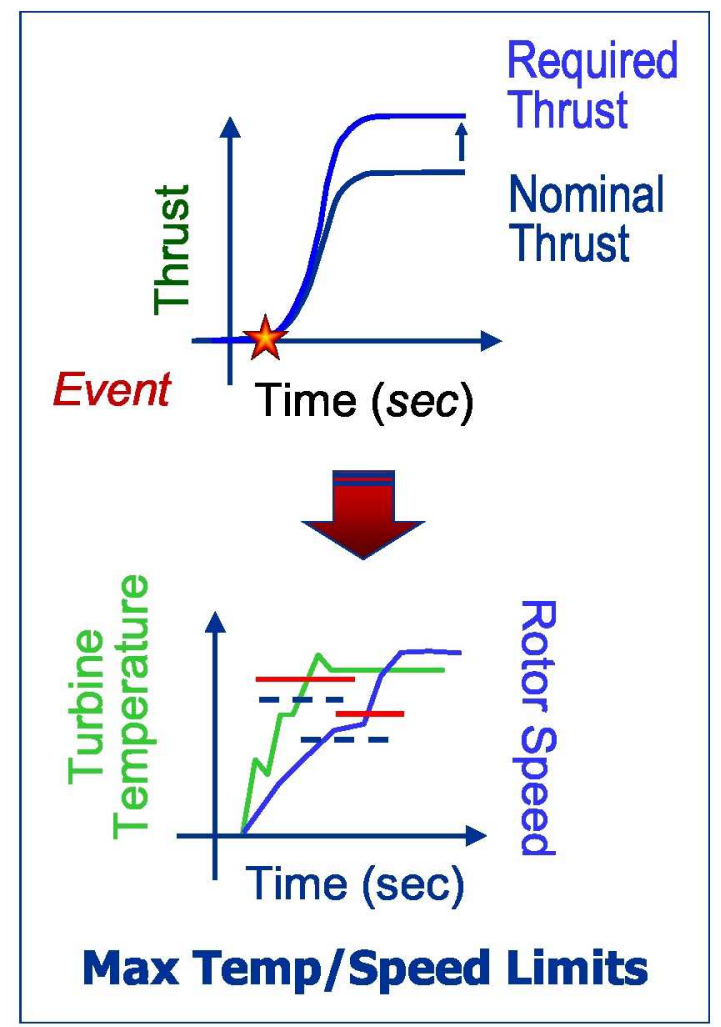

2 Rudder/Tail Failure

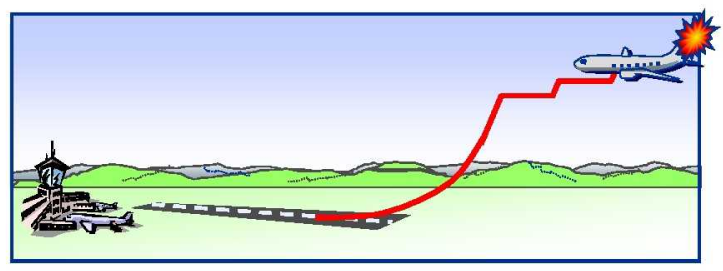

Requiring Faster

Response
Event

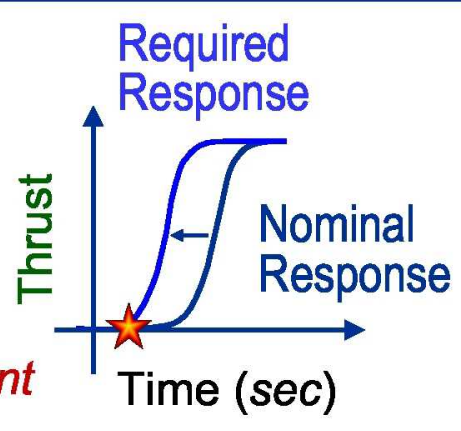

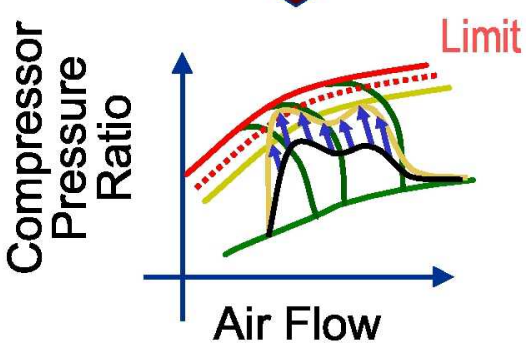

Stall / Surge Margins

Figure 1.-Two types of engine responses: overthrust and fast thrust.

normal and fast transient response on a compressor map; the fast response comes much closer to the operational limit by disregarding some of the safety margin set aside, at the expense of increased risk of stall (Ref. 9).

As a precursor to modifying the engine control to achieve these two objectives, a sensitivity analysis must be performed that investigates the trade-offs between performance and impact. Performance is defined as increase in response speed or increased maximum thrust level, while impact is defined as the reduction in stall margin and component life. This sensitivity study has two functions: it can enable the development of predefined controllers for specific situations, but more broadly it determines what the best achievable result in certain scenarios is and if a control solution even exists. 


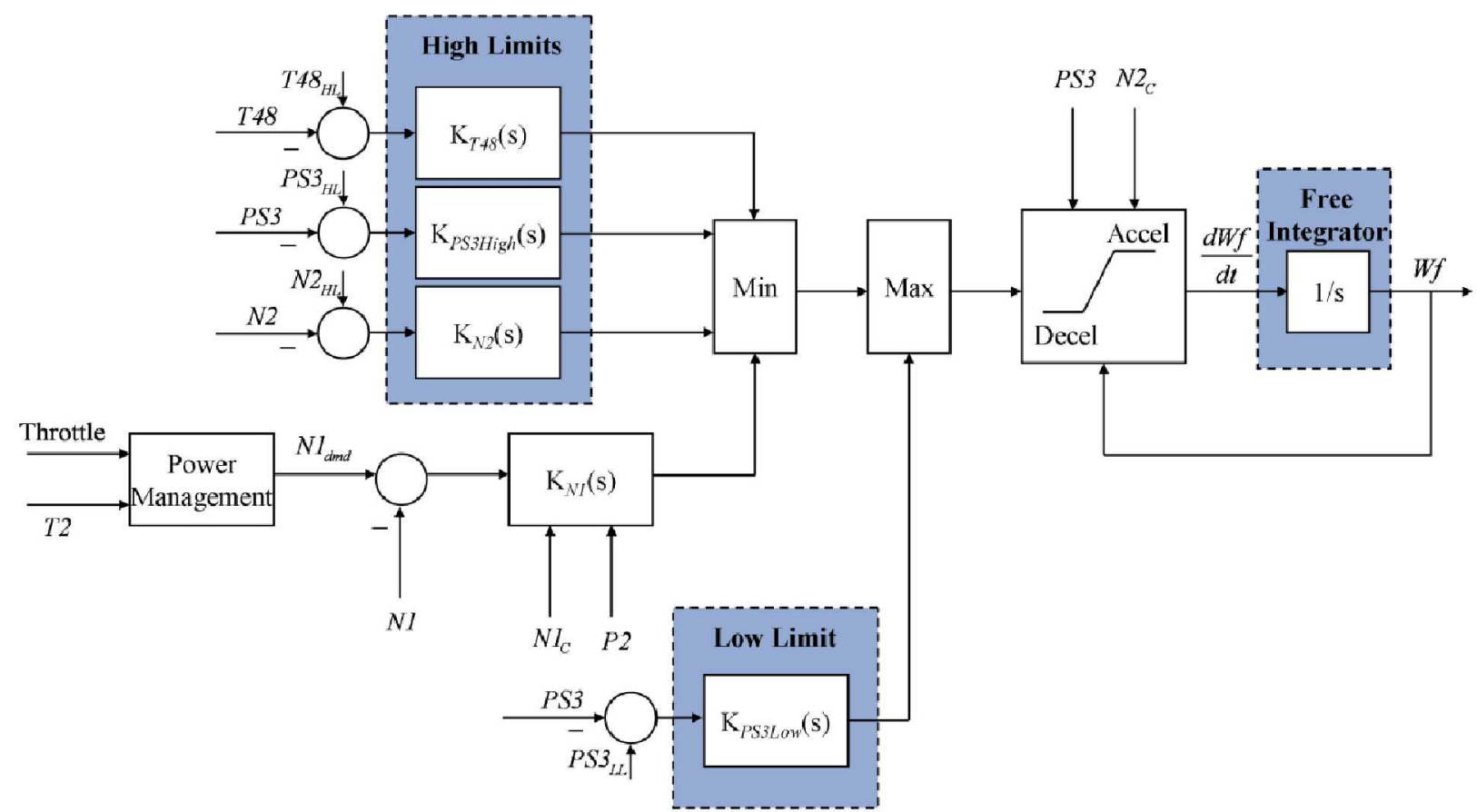

Figure 2.-Typical turbofan engine controller architecture. P2 and T2 are used for parameter correction; the subscript $C$ indicates a corrected parameter and the variable $N 1_{d m d}$ represents the fan speed setpoint. The subscripts $H L$ and $L L$ indicate High Limit and Low Limit, respectively.

One approach to improve the thrust response of turbofan engines in emergency situations is to allow a faster change in fan speed through the use of adaptive controller limits. The controller limits are determined such that they maintain various safety margins during operation, over the life of the engine. These include structural limits on internal engine temperatures and speeds, and operability limits on stall margins. Structural limits are set to provide a suitably small probability of failure over the life of the engine. A control architecture to protect operability limits adaptively has been proposed (Ref. 10) that enables the manipulation of other limits in order to trade off life for performance. Another option to speed up the thrust response is to allow faster throttle changes. The throttle is usually rate limited or low-pass filtered to slow down the change in demand.

Figure 2 shows a representative controller architecture for a turbofan engine (Ref. 11); this specific controller will be discussed in detail in a later section. In general, the engine has several control modes as well as limits. For steady state operation and small perturbations about steady state, the fan speed or engine pressure ratio is controlled using a relatively low bandwidth controller to a value indicated by the throttle setting. For transient operation, the rotor acceleration could be controlled as a function of its speed; this is called NDOT control. NDOT control lends itself well to turbofan engine use because acceleration time is consistent and repeatable around the flight envelope (Ref. 12); it is independent of engine deterioration and engine heat state, and it reduces mechanical stress as compared to other transient control methods (Ref. 13). A consequence of the repeatability of the acceleration throughout the life of the engine is that the acceleration schedule must be designed to allow the engine to follow without encountering a stall or over-temperature condition, independent of deterioration level. This means that a new engine's response is slowed down on purpose to the point that the most deteriorated engine in the fleet can still achieve. An acceleration schedule is overridden by the limit logic and fuel flow is adjusted to maintain safe operation if engine variables get too close to a limit, which is often the case with large, rapid thrust transients (Ref. 12). A relatively new or above average engine with an NDOT acceleration schedule has the potential for its speed of response to be improved safely through schedule adjustment in emergency situations.

Structural limits are designed to allow the engine to achieve a certain life at a specified probability of failure. Even an engine whose life is fully consumed by definition (the life limit in terms of number of cycles is reached) will have a minute probability of failure and for a newer engine the probability of failure may be orders of magnitude smaller. In fact, 80 percent of parts replaced at low-cycle fatigue (LCF) calculated safe-life limits have at least a full order of magnitude of fatigue life remaining (Ref. 14). However, if structural limits such as critical temperature limits are exceeded, the part life remaining can be reduced beyond the debit due to normal usage. This increases the risk of failure and procedures involving maintenance actions such as inspections are prescribed (Ref. 15). 
As shown in Figure 2, the control system is usually implemented with a free integrator at the output. This allows the control signals that are generated by the schedules and regulators to be incremental commands. The output of the free integrator is the actual fuel flow command. This approach eliminates integrator windup (Ref. 16).

For emergency situations, engine operation beyond the normal envelope could be desirable if it enables improved flight control, thereby increasing the chance of survival, even at the potential expense of engine life. Under the IRAC project, the flight control system seeks to integrate the propulsion system as an additional control effector in emergency situations. It evaluates the damaged vehicle and requests thrust based on a determination of what is required to land safely. The propulsion control must meet the demand, if possible, by trading off risk.

As previously stated, the limit logic in the controller protects the engine's structural and operability limits. Structural limits prevent the engine from overstressing its components, in terms of speed, acceleration, and temperature. Stress can result in premature failure, which poses a safety risk. Life-limited parts of the engine are retired for time once they accumulate a specified number of flight cycles. This keeps the probabilistic chance of failure at an acceptable level assuming a standard flight profile (Ref. 17). If controller bandwidth were to be increased and structural limits were to be relaxed for emergency operation, a fairly new engine could respond faster and the probability of failure could still be kept acceptably small, since it has most of its life remaining, in a probabilistic sense. Even an older engine could respond faster with a slightly reduced structural safety margin. Overthrust operation is potentially much more detrimental to engine life than fast response operation is because the limit exceedance is continuous rather than transient and intermittent.

For the IRAC application, the standard Bill of Material (BOM) controller is modified for beyond normal operation only. That is, there should be no apparent change for normal operation, but overall flight safety is enhanced for emergency conditions, even at the expense of engine life. The paper will discuss the potential for improved performance through increased controller bandwidth and relaxation of limits, and the consequences for engine life.

It must be noted that what will be emphasized here is the improvement in the acceleration time. While there may be some flexibility with the deceleration schedule, in general there is little discretion in the deceleration limit logic since the limits are set to maintain the minimum fuel flow to avoid combustor blowout (Refs. 12 and 13). Thus the engine may already decelerate as quickly as possible, which is the best situation from the point of view of this effort. As an aside, in order to execute flight maneuvers using only the engines, it is necessary to move the throttles together (for lateral control) as well as differentially (for longitudinal and yaw control). Previous research with propulsion-controlled aircraft has shown (Ref. 4) that sometimes movement of all throttles together (not differentially) can induce a small yawing moment, even if all throttles are reduced by the same amount; this is probably because of unequal thrust decrease or differing engine response. However, it must be pointed out that uneven response was only reported in similar throttle movements, not split throttles. This is because similar movements should not induce imbalance, while split throttles are designed to induce imbalance so differing engine response would not necessarily even be noticeable. For example, in Reference 4 full differential throttle to produce roll was evaluated with a Northrop T-38. Here the response was described only in terms of steady state roll rate, so even with this large thrust imbalance, no unusual or unexpected response was noted. For the B-727 Commercial Jet Transport, change in roll rate was examined after a throttle split to full differential thrust. Here only an initial lag was reported. This leads to the conclusion that matching response speed for differential throttle movement is not critical and an engine response that is as fast as possible is an appropriate goal.

The rest of this paper is organized as follows. First, the demonstration model, the Commercial Modular AeroPropulsion System Simulation (C-MAPSS) engine, will be described. Next the C-MAPSS control system will be described in terms of what can be modified to improve response characteristics. Next, results of modifying the fan speed control, and then the controller schedules for faster response, and enabling overspeed operation for overthrust will be presented. This is followed by a discussion of the results and finally conclusions.

\section{The C-MAPSS Model}

C-MAPSS represents a conceptual 90,000-lb thrust class turbofan engine with high bypass ratio and a two-spool configuration (Ref. 11). The simulation includes a controller that is representative of the control logic within a Full Authority Digital Engine Controller (FADEC) on board current commercial engines. The closed-loop C-MAPSS engine can be used to demonstrate the type of sensitivity analysis that would need to be performed in order to produce an enhanced control system for the type of fast response and overthrust operation required to recover and safely land an airplane from an upset or damage situation. Although the C-MAPSS results are 
illustrative, each model of engine and its controller is different, with operational and life considerations that vary from model to model and may not even have been considered in the design of the C-MAPSS controller. Therefore the methodology rather than the specific results is of interest. The structure of the C-MAPSS controller is typical, albeit simplified, of the type of controller commonly used on commercial turbofan engines. The main features are the fan speed controller with associated limit logic, and the acceleration/deceleration schedules with their associated limits. The throttle is rate limited to $150^{\circ} / \mathrm{sec}$, which is already so fast that increasing it will not improve response time. Examples will be given of the modification of the controller limits, and the impact of these changes on engine response and thrust level will be investigated in this paper as a guide for the type of adjustments available to the designer.

The flight envelope of the C-MAPSS engine is shown in Figure 3, along with some transient fan speed responses to throttle movements at various points within the flight envelope. It is clear that the engine responds much more slowly at higher altitude than at lower altitude. This can be attributed to the low air density at these conditions, and is expected. At high altitudes, the engine responds slowly, regardless of what the control system tries to do. If the acceleration limiter is modified, the engine might respond somewhat faster, but at the expense of a lower stall margin, which is the type of trade-off that the IRAC project seeks to exploit. Table 1 gives some time response data for the plots shown in Figure 3. The values in the last three columns are defined as in Reference 18.

Other variables affect the engine response as well. For instance, ambient conditions such as temperature have an impact on the engine response. Simulation results at $30000 \mathrm{ft}$ and Mach 0.77 over a sea level temperature range of -30 to $90{ }^{\circ} \mathrm{F}$ yielded only about $0.2 \mathrm{sec}$ difference in time to reach 90 percent for a throttle increase from 40 to 90 ,

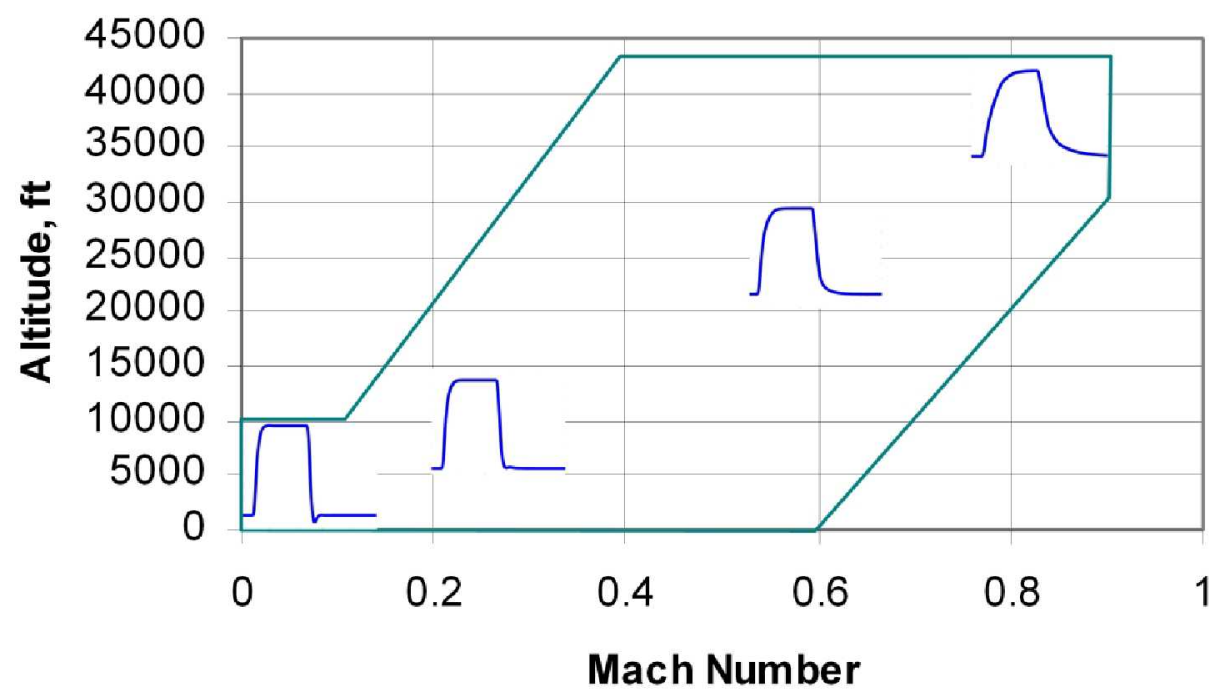

Figure 3.-C-MAPSS flight envelope with sample fan speed responses.

TABLE 1.-ENGINE FAN SPEED RESPONSE TIME INFORMATION FOR VARIOUS POINTS IN THE FLIGHT ENVELOPE

\begin{tabular}{|c|c|c|c|c|c|}
\hline $\begin{array}{c}\text { Alt, } \\
\mathrm{ft}\end{array}$ & Mach & $\begin{array}{c}\text { TRA, } \\
\text { deg }\end{array}$ & $\begin{array}{c}\text { Delay time, } \\
\text { sec }\end{array}$ & $\begin{array}{c}\text { Rise time, }^{\mathrm{b}} \\
\text { sec }\end{array}$ & $\begin{array}{c}\text { Settling time, } \\
\text { sec }\end{array}$ \\
\hline 0 & 0 & $40 \rightarrow 100$ & 0.72 & 1.13 & 2.02 \\
\hline 0 & 0 & $100 \rightarrow 40$ & 0.70 & 0.68 & 2.10 \\
\hline 10000 & 0.25 & $40 \rightarrow 100$ & 0.78 & 1.25 & 2.41 \\
\hline 10000 & 0.25 & $100 \rightarrow 40$ & 0.76 & 0.93 & 1.63 \\
\hline 25000 & 0.62 & $40 \rightarrow 100$ & 0.94 & 1.95 & 2.51 \\
\hline 25000 & 0.62 & $100 \rightarrow 40$ & 1.00 & 1.83 & 4.48 \\
\hline 42000 & 0.84 & $40 \rightarrow 100$ & 1.63 & 3.66 & 6.27 \\
\hline 42000 & 0.84 & $100 \rightarrow 40$ & 1.60 & 4.52 & 9.63 \\
\hline
\end{tabular}

${ }^{a}$ Delay time: Time required for the response to reach 50 percent of its total transition

${ }^{b}$ Rise time: Time required for response to rise from 10 to 90 percent of its total transition

${ }^{\text {c}}$ Settling time: Time required for a response to reach and remain within the final

2 percent of its transition 
and a $0.1 \mathrm{sec}$ difference back down. Another variable that impacts response time is deterioration. Engine deterioration is a process that occurs over time due to use and wear. It manifests itself as a reduction in efficiency and change in flow capacity of the engine components, and is measured by exhaust gas temperature increase. A several percent change in the components' efficiency and flow capacity will result in the need for an engine overhaul. The fan speed response is slightly affected by the level of deterioration of the engine. Sea level static (SLS) simulation testing was performed for TRA changes from 100 to 40 and back. There is a slight increase in the fan speed response time with engine deterioration when the throttle is retarded. However, for a throttle increase, the fan speed response of a deteriorated engine takes half a second longer to settle than a new engine's does. The latter result is certainly due to the controller, where limiting occurs with the more deteriorated engine. This is because of the effect of deterioration on the trim values of uncontrolled variables: temperature and speeds increase, stall margins decrease. Stall margin statistics for example responses at various levels of deterioration are presented in Table 2 for throttle decrease and in Table 3 for throttle increase. From Table 2 it is obvious that a 5 percent shift in the components' efficiency and flow capacity is the limit of deterioration that the C-MAPSS engine can handle. This also demonstrates the inability to improve the deceleration response in the C-MAPSS engine since there is no flexibility to adjust the deceleration schedule.

TABLE 2.-DETERIORATION LEVELS ${ }^{\mathrm{a}}$ AND MINIMUM LPC STALL MARGIN FOR DECREASE IN TRA FROM $100^{\circ}$ TO $40^{\circ}$ AT SLS

\begin{tabular}{|c|c|}
\hline $\begin{array}{c}\text { Deterioration level, } \\
\text { percent }\end{array}$ & $\begin{array}{c}\text { Minimum LPC stall margin, } \\
\text { percent }\end{array}$ \\
\hline 0 & 3.4 \\
\hline 1 & 2.6 \\
\hline 2 & 1.9 \\
\hline 3 & 1.2 \\
\hline 4 & 0.5 \\
\hline 5 & 0 \\
\hline
\end{tabular}

${ }^{a}$ Shifts in efficiency and flow capacity.

TABLE 3.-DETERIORATION LEVELS ${ }^{\mathrm{a}}$ AND MINIMUM HPC STALL MARGIN FOR INCREASE IN TRA FROM $40^{\circ}$ TO $100^{\circ}$ AT SLS

\begin{tabular}{|c|c|}
\hline $\begin{array}{c}\text { Deterioration level, } \\
\text { percent }\end{array}$ & $\begin{array}{c}\text { Minimum HPC stall margin, } \\
\text { percent }\end{array}$ \\
\hline 0 & 14.8 \\
\hline 1 & 13.7 \\
\hline 2 & 12.6 \\
\hline 3 & 11.2 \\
\hline 4 & 9.8 \\
\hline 5 & 8.3 \\
\hline a'Shifts in efficiency and flow capacity.
\end{tabular}

It was mentioned in Reference 4 that the engines that were tested responded sluggishly at very low power. This may be due to stall margin considerations and an NDOT acceleration schedule that must account for a worst case engine. Thus this time delay is a feature of the controller. In contrast, the C-MAPSS engine has a small combustion delay of about $0.04 \mathrm{sec}$ which is a feature of the engine itself and cannot be overcome by controller modification. The response of the C-MAPSS engine is not sluggish in the very low power region because its stall margin model is not particularly sensitive to very low power operation, so its controller does not need to restrict acceleration as severely as those of the engines tested in Reference 4. Because of this, responses beginning at very low power will not be addressed in this paper, but the approach that will be demonstrated would be the same for that region. As mentioned earlier, for a new or above average engine, there is a lot of potential for improvement in response in this region.

\section{The C-MAPSS Controller}

A modern controller on a high bypass turbofan engine typically is of the general form depicted in Figure 2. It consists of multiple loops that control to various setpoints or limits as the situation dictates. The inputs in this example are throttle position and representative temperature, pressure, and shaft speed sensor measurements. The 
core speed $(N 2)$ limit is designed to prevent mechanical failure of the rotating components, while compressor exit static pressure (PS3) and high pressure turbine outlet temperature (T48) high limits are set to prevent failure of the high pressure and high temperature components. A PS3 low limit regulator is instituted to prevent lean combustor blowout. The fan speed regulator and the high and low limit regulators are shown as transfer functions $\mathrm{K}_{x}(\mathrm{~s})$. The acceleration and deceleration schedules are simply limiters in this case. The output is the fuel flow command. A gain-scheduled controller for fan speed is active in the neighborhood of a steady state operating point. As the engine deviates from steady state, due usually to a throttle transient, other control loops come into play. These loops protect the engine from over-speed, over-temperature, stall, combustion blowout, etc. Each loop computes a fuel flow increment assuming that it is the active controller. The appropriate increment is selected by the logic, as shown in Figure 2, based on the operating point of the engine, and the free integrator updates the total fuel flow command by this amount. For instance, if a throttle transient causes a measured temperature to approach its maximum allowed value as fan speed is increasing, the temperature-limiting loop will be selected to regulate the temperature to the limit, rather than allow fan speed to continue rising, as commanded by the throttle. It is important to understand that the regulator loops are always on, each providing a control signal as if it were the active regulator. Thus a limiting regulator will become active before a limit is reached. The regulator loops are all separate and may be designed independently (Ref. 19). The limits may be functions of the operating point, and are generally set to enable safe operation over the useful life of the engine, independent of age.

The structure, as shown in Figure 2, selects the minimum fuel increment of the fan speed regulator and the high limit regulators, and then selects the maximum of that and the fuel flow increment from the low limit regulator. The high limit regulators are incorporated in parallel, as are the low limit regulators, so adding a new one is simply a matter of inserting a new regulator loop into the appropriate selection logic.

Engine controllers use a variety of limits and implementations depending on the manufacturer and type of engine, but the common objective is to maintain safe and efficient operation for the life of the engine. This is accomplished through the use of acceleration/deceleration schedules and limits on measurable or computed variables. An example of a computed variable is the ratio of fuel flow, $W f$, to compressor exit static pressure, $P S 3$, sometimes called $\Phi=$ WfIPS3. The variable $\Phi$ is a particularly useful quantity because it provides good control of turbine temperature, good reaction to stall, and good reaction to burner blowout (Ref. 13). In the C-MAPSS controller, the acceleration/deceleration schedule is simply a $\Phi$ limit scheduled as a function of corrected core speed $N 2_{C}$, determined by testing to maintain a minimum stall margin. When the $\Phi$ limit is reached, the fuel flow increment is set to zero, maintaining fuel flow at the current level for that time step.

\section{Results}

An example sensitivity analysis has been performed on the C-MAPSS engine to investigate its ability to respond more quickly than normal, as well as to provide overthrust capability. Three distinct cases are addressed: small throttle movement fan speed control, large throttle movement acceleration schedule control, and overspeed control.

For small throttle changes, the fan speed controller's bandwidth may be increased to determine the engine's performance capabilities and the corresponding changes in critical variables that act to limit the response speed. These controllers are tested on small throttle changes, within the linear range. This gives an improvement in response without the interference of controller limits, and demonstrates the true capability of the engine.

Next, larger transients are investigated. These responses utilize the acceleration schedule, and the limit regulators also come into play. Manipulation of the limits and schedule enables faster response for large throttle transients.

Finally, the overthrust case is analyzed. Here the concern is for producing more thrust at the expense of engine life, which is also achieved by relaxing controller limits.

\section{Small Throttle Transients}

The fan speed control is active in the vicinity of the fan speed setpoint. It is a linear gain-scheduled controller designed to achieve a certain bandwidth response in the linear range. Thus, as long as no limits are encountered, the response can be significantly improved just through a redesign that increases the bandwidth of the closed loop system. However, the linear range is very small, as shown by the top plot in Figure 4, where limit regulators become active for a throttle movement of as little as $5^{\circ}$. Examining Figure 4 gives insight into what is happening inside the controller, which is necessary to understand before modifying the controller design. It can be seen that as system bandwidth increases, the response gets faster, but as bandwidth is increased further, the response slows down and becomes sluggish. This surprising result can be understood by looking at the middle plot in Figure 4 which shows 

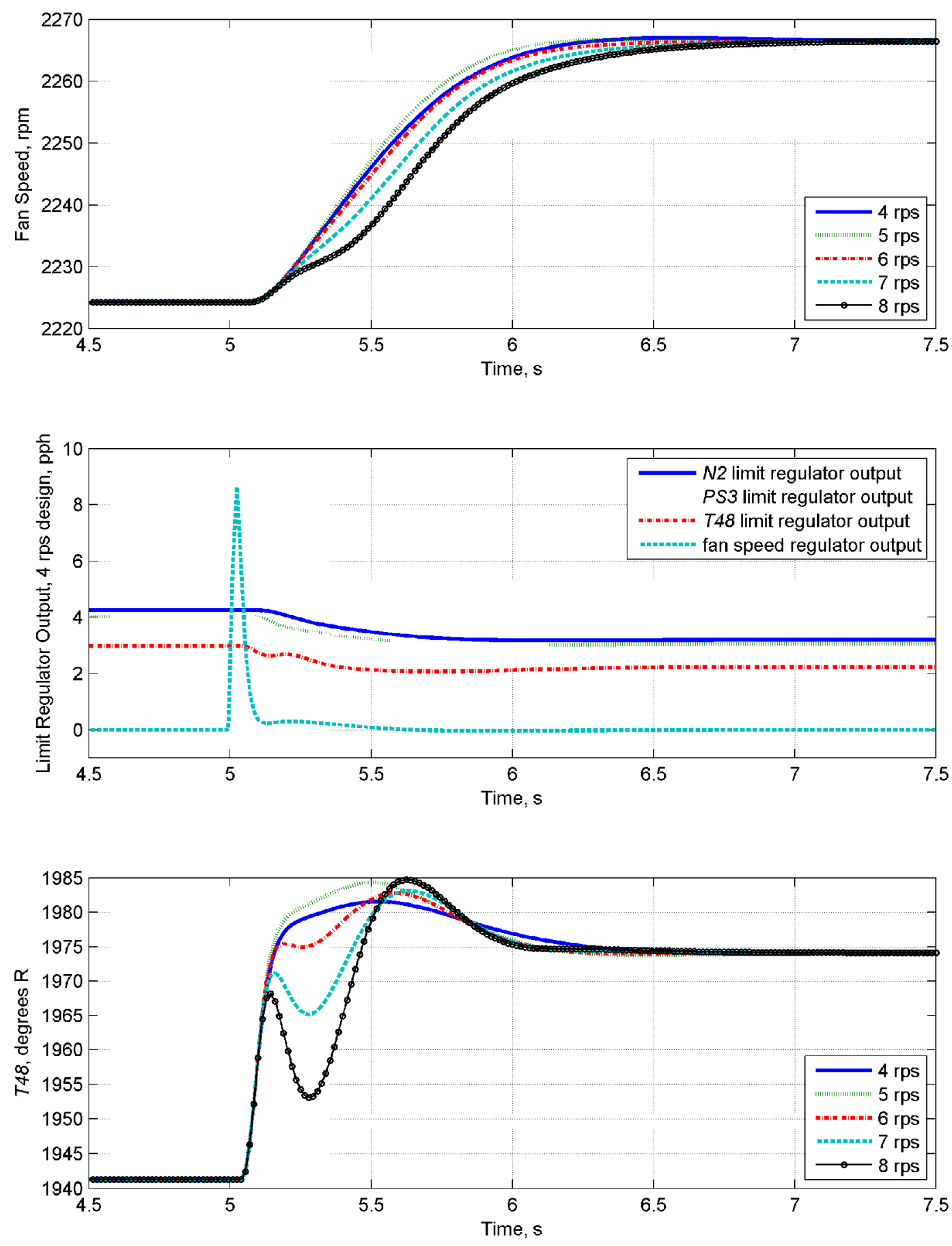

Figure 4.-Responses to a TRA step change of $5^{\circ}$ at $5 \mathrm{sec}$. Top: Fan speed responses for engine with controllers designed for different bandwidths and standard limits in place. All responses are slowed by T48 limit regulator. Middle: Output of limit regulators designed for 4 rps responses. The minimum value is selected at each time step. Bottom: $T 48$ responses for engine with controllers designed for different bandwidths. Nominal T48 limit is $2072^{\circ} \mathrm{R}$. 
the outputs of the fan speed regulator and the high limit regulators. Recall that the high limit regulators are always running, and the minimum value is selected as the fuel flow increment. As can be seen in the plot, even with the 4 rps controller, the $T 48$ regulator becomes active for a short time after the throttle change. As the bandwidth of the controller is increased, the T48 regulator slows the response even more. What is particularly interesting about this is shown in the bottom plot in Figure 4: in no case does $T 48$ ever get near its limit of $2072{ }^{\circ} \mathrm{R}$. Compare this to Figure 5, where the limits have been relaxed to allow linear operation. In Figure 5 responses are significantly faster, meaning that if the limits can be moved, great improvement in speed can be achieved for small throttle movements. In only the 8 rps case does $T 48$ actually exceed its limit, and only for fraction of a second, which is insignificant for time-at-temperature failure modes. Neither core speed nor PS3 is near its limit. Also, even though the overshoot corresponding to the closed-loop system's design damping ratio of 0.7 increases with bandwidth, it remains at a reasonable level for a commercial engine. Thus even the $8 \mathrm{rps}$ case with limits relaxed should be considered a safe and acceptable response.

The importance of Figure 5 is that it gives an indication of the response that the engine is able to achieve without limits, and thus what a fast response controller may be designed to accomplish, even though over a relatively small range of throttle movement. Table 4 gives statistics for the fan speed responses in Figure 5. It is interesting to note that the fastest response in Figure 4 is slower than the slowest response in Figure 5. Of course the attainable response may vary around the flight envelope, so this analysis should be performed at multiple operating points.

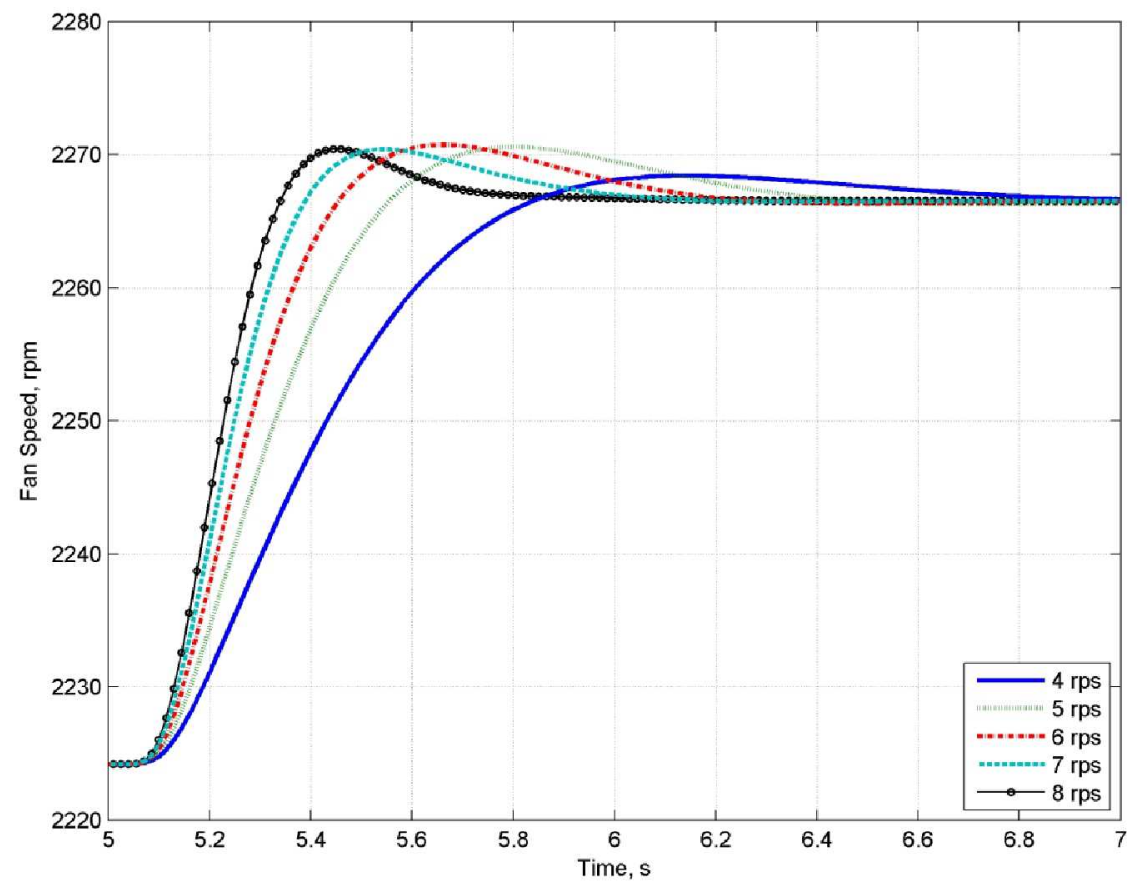

Figure 5.-Fan speed responses for engine with controllers designed for different bandwidths, TRA step of $5^{\circ}$ at $5 \mathrm{sec}$, and limits relaxed. Response is linear.

TABLE 4.-FAN SPEED RESPONSE TIME STATISTICS USING CONTROLLERS DESIGNED FOR DIFFERENT BANDWIDTHS, TRA CHANGE FROM $80^{\circ}$ TO $85^{\circ}$ WITH NO LIMITS AS SHOWN IN FIGURE 5

[These are linear responses.]

\begin{tabular}{|c|c|c|c|}
\hline $\begin{array}{c}\text { Closed-loop } \\
\text { system design } \\
\text { bandwidth, } \\
\text { rps }\end{array}$ & $\begin{array}{c}\text { Delay time, } \\
\text { sec }\end{array}$ & $\begin{array}{c}\text { Rise time, } \\
\text { sec }\end{array}$ & $\begin{array}{c}\text { Settling time, } \\
\text { sec }\end{array}$ \\
\hline 4 & 0.370 & 0.495 & 0.805 \\
\hline 5 & .295 & .315 & .550 \\
\hline 6 & .250 & .255 & .445 \\
\hline 7 & .235 & .210 & .385 \\
\hline 8 & .220 & .180 & .340 \\
\hline
\end{tabular}




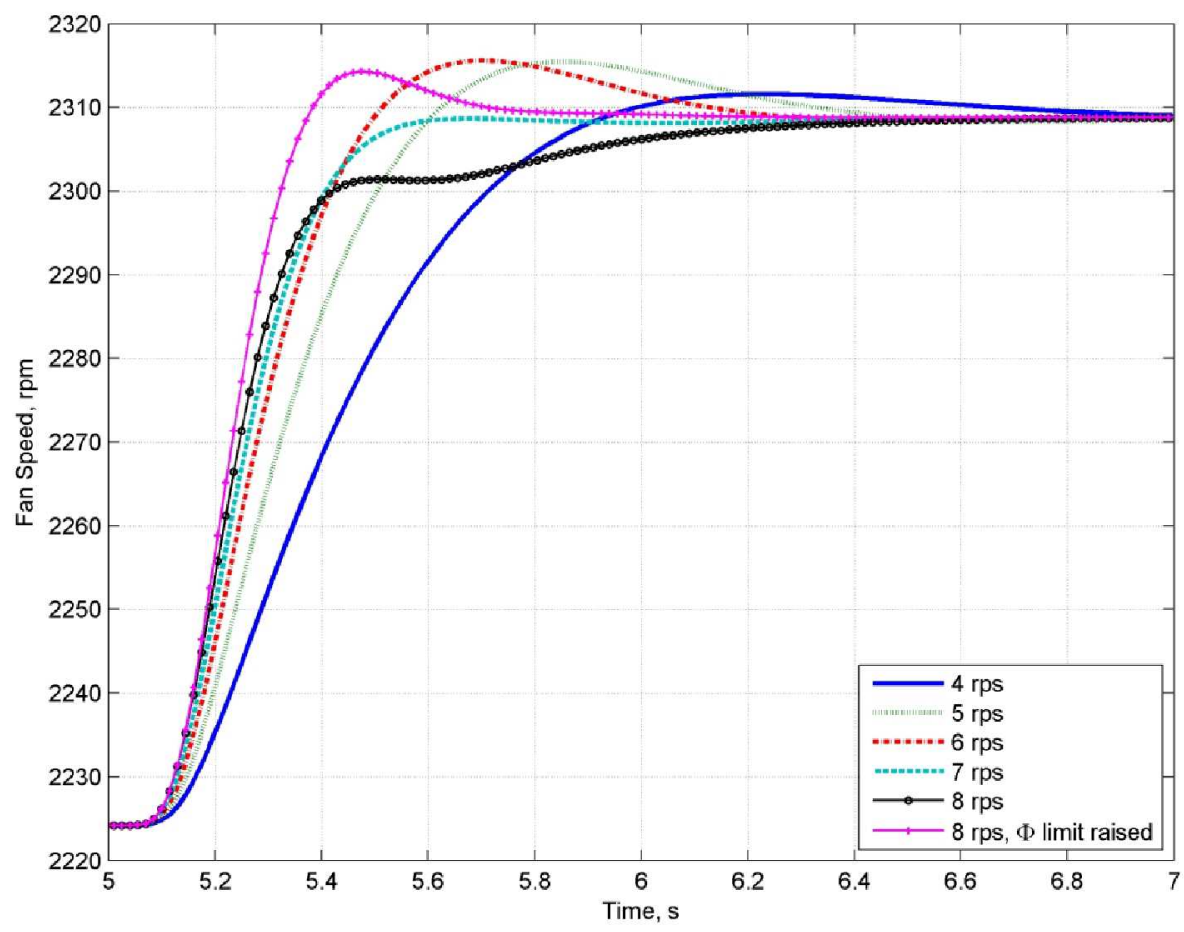

Figure 6.-Fan speed responses for engine with controllers designed for different bandwidths, TRA change of $10^{\circ}$ at $5 \mathrm{sec}$ and no high limits, only $\Phi$ limit. The $\Phi$ limit is raised for one run using the controller designed for a system bandwidth of $8 \mathrm{rps}$.

Figure 6 shows the fan speed response to a TRA increase of $10^{\circ}$ with the high limits relaxed, the same as in Figure 5. Here however, the fan speed responses obtained using the higher bandwidth controllers are distorted because the $\Phi$ limit is hit. This indicates that the linear range for high bandwidth controllers with high limits removed ends somewhere between $5^{\circ}$ and $10^{\circ}$ of TRA increase. The final trace in Figure 6 shows the fan speed response with the $\Phi$ limit moved, as well. This response looks similar to the linear 8 rps response in Figure 5, and again, only the $T 48$ limit is briefly violated.

\section{Large Throttle Transients}

The acceleration/deceleration schedules are the nonlinear portion of the C-MAPSS controller and are encountered when the throttle movement is large enough to exceed the linear range of the fan speed control. In the C-MAPSS controller, the schedules consist of limits on the variable $\Phi=W f / P S 3$ as a function of corrected core speed, N2. These limits are designed specifically to maintain a minimum stall margin during acceleration or deceleration. Adjustment of the $\Phi$ limit directly affects the engine response. In the C-MAPSS controller, these schedules are very simple; they pass through the fan speed controller or limit regulator fuel flow increment until a $\Phi$ limit is reached, at which point the fuel flow increment is set to zero. This keeps $\Phi$ within a defined range, which is set based on desired stall margin. If the stall margin can be reduced, as is the case for a new (undeteriorated) engine or for small to medium throttle movements (Ref. 10), these limits can be relaxed. As with the linear fan speed controller, adjustment of the $\Phi$ limits is not arbitrary and requires an understanding of what is going on within the specific engine and controller. The idea that the limit can be relaxed under emergency conditions stems from the fact that the deviation in stall margin depends upon the size and speed of the throttle movement, and the stall margin at a given operating point depends upon the engine's deterioration level. Thus in general the $\Phi$ limits should be set to accommodate the largest, fastest throttle excursion possible for the most deteriorated engine. Since the C-MAPSS engine controller's acceleration/deceleration schedules only restrict fuel flow when the $\Phi$ limit is reached, i.e., the fan speed control increment is passed through as long as no limit is reached, relaxing the $\Phi$ limits with adequate stall margin remaining still provides safe operation.

During large transients, there is complex interaction within the controller, due to the multiple regulators operating in parallel as well as the acceleration/deceleration schedules. To analyze such transients for the purpose of potentially improving the response time, it is important to determine which limits are being hit. A test case with a 
relatively large TRA movement of $60^{\circ}$ is used as an example. Here TRA is moved from $20^{\circ}$ to $80^{\circ}$ as fast as possible $\left(150^{\circ} / \mathrm{sec}\right)$. Variations were made to the controller in terms of the fan speed regulator design (bandwidth increase from 4 to $7 \mathrm{rps}$ ), $\Phi$ limit relaxation, and finally $T 48$ limit relaxation from 2072 to $2300^{\circ} \mathrm{R}$. The transients are described in Table 5 in terms of some of their thrust performance, and life and operability characteristics.

The top plot in Figure 7 shows the fan speed responses that correspond to the cases in Table 5, the second plot shows the corresponding $T 48$ values, the third and bottom plots show $\Phi$ versus corrected $N 2$ and HPC stall margin response, respectively, for three of the cases. Case 1 is the response with the nominal control. The fan speed control
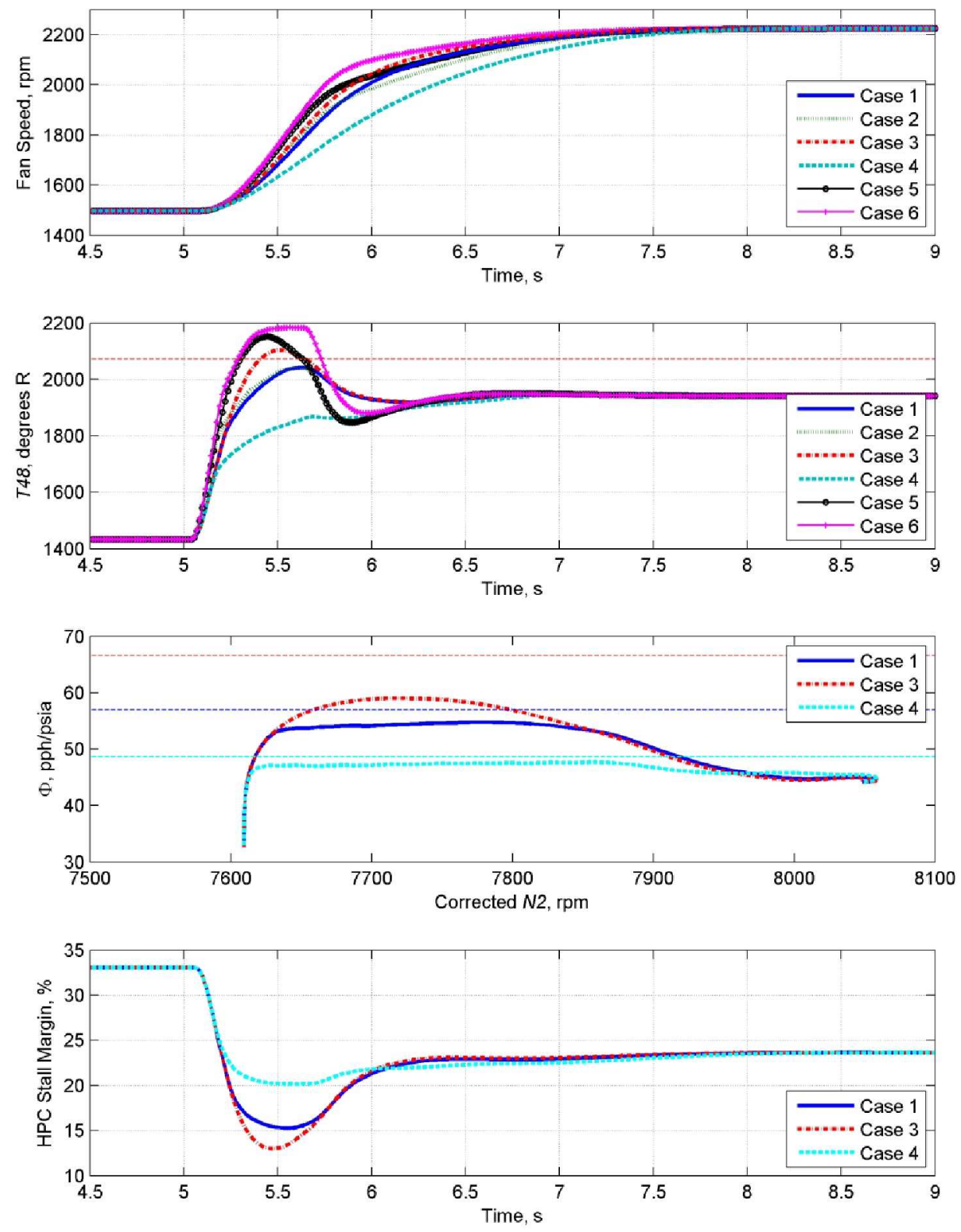

Figure 7.-Responses for TRA step of $60^{\circ}$ at $5 \mathrm{sec}$. Top: Fan speed responses for the cases in Table 5. Second: 748 responses for the cases in Table 5 . The dotted horizontal line represents the nominal T48 limit, which was raised to $2300^{\circ}$ for Case 6 only. Third: $\Phi$ versus Corrected $N 2$ responses for three cases in Table 5. The dotted horizontal lines represent the maximum $\Phi$ limits, matched by color to their corresponding case. Bottom: HPC stall margin responses for three cases in Table 5. 
TABLE 5.-CHARACTERISTICS OF FAN SPEED RESPONSES AT SLS STANDARD DAY WITH NOMINAL CONTROLLER AND CONTROLLER VARIATIONS, TRA STEP FROM $20^{\circ}$ TO $80^{\circ}$ AT 5 SEC

\begin{tabular}{|c|c|c|c|c|c|c|c|c|}
\hline Test case & $\begin{array}{l}\text { Delay } \\
\text { time, } \\
\text { sec }\end{array}$ & $\begin{array}{c}\text { Rise } \\
\text { time, } \\
\text { sec }\end{array}$ & $\begin{array}{l}\text { Settling } \\
\text { time, } \\
\text { sec }\end{array}$ & $\begin{array}{l}\text { Min HPC } \\
\text { stall } \\
\text { margin, } \\
\text { percent }\end{array}$ & $\underset{{ }^{\circ} \mathrm{Max} T 48,}{\mathrm{R}}$ & $\begin{array}{l}\text { Max } \\
P S 3, \\
\text { psia }\end{array}$ & $\begin{array}{c}\text { Max } \\
\text { core } \\
\text { speed } \\
N 2 \text {, } \\
\text { rpm }\end{array}$ & $\begin{array}{l}\text { Max fan } \\
\text { speed } N 1, \\
\operatorname{rpm}\end{array}$ \\
\hline $\begin{array}{l}\text { Case } 1 \\
\text { Nominal acceleration limit } \\
4 \text { rps fan speed controller } \\
\text { Nominal } T 48 \text { limit }\end{array}$ & 0.75 & 1.32 & 2.34 & 15.3 & 2042 & 448 & 8838 & 2224.2 \\
\hline $\begin{array}{l}\text { Case } 2 \\
\text { Nominal acceleration limit } \\
7 \text { rps fan speed controller } \\
\text { Nominal } T 48 \text { limit }\end{array}$ & 0.72 & 1.47 & 2.43 & 15.3 & 2040 & 448 & 8838 & 2224.2 \\
\hline $\begin{array}{l}\text { Case } 3 \\
\text { Increased acceleration limit } \\
4 \text { rps fan speed controller } \\
\text { Nominal } T 48 \text { limit }\end{array}$ & 0.69 & 1.19 & 2.25 & 13.0 & $\begin{array}{c}2104 \\
\text { (limit } \\
\text { exceeded) }\end{array}$ & 449 & 8838 & 2224.2 \\
\hline $\begin{array}{l}\text { Case } 4 \\
\text { Reduced acceleration limit } \\
4 \text { rps fan speed controller } \\
\text { Nominal } T 48 \text { limit }\end{array}$ & 0.97 & 1.67 & 2.65 & 20.1 & 1951 & 449 & 8838 & 2224.2 \\
\hline $\begin{array}{l}\text { Case } 5 \\
\text { Increased acceleration limit } \\
7 \text { rps fan speed controller } \\
\text { Nominal } T 48 \text { limit }\end{array}$ & 0.63 & 1.23 & 2.11 & 11.5 & $\begin{array}{c}2152 \\
\text { (limit } \\
\text { exceeded) }\end{array}$ & 448 & 8837 & 2224.2 \\
\hline $\begin{array}{l}\text { Case } 6 \\
\text { Increased acceleration limit } \\
7 \text { rps fan speed controller } \\
T 48 \text { limit raised to } 2300^{\circ} \mathrm{R}\end{array}$ & 0.61 & 1.01 & 1.92 & 11.1 & 2193 & 448 & 8837 & 2224.2 \\
\hline
\end{tabular}

is overridden for a short time by the $T 48$ regulator as the temperature approaches the limit. From the third plot in Figure 7 it can be seen that the acceleration limit becomes active by the sudden flattening out of the $\Phi$ curve. Case 2 is the same as Case 1 except that the 4 rps linear fan speed controller is replaced with a 7 rps controller. This has a faster initial response but slows down as it approaches the $T 48$ limit and then rides the acceleration limit. It actually underperforms Case 1 in terms of rise time and settling time. Case 3 uses the nominal fan speed controller, but the $\Phi$ limit is modified to allow faster response at the expense of a small penalty in stall margin (bottom plot in Figure 7). The T48 limit is exceeded but the response is the fastest of the three from beginning to end. From the third plot in Figure 7 it is clear from the smooth rounded $\Phi$ curve that the acceleration limit does not come into play in this transient response. For Case 4, the acceleration limit was moved the other way, and the response is significantly slowed down, with $T 48$ remaining low as well. The third plot in Figure 7 shows the severe flattening of the $\Phi$ curve, which is the cause of the slow response. In Case 5, the acceleration limit of Case 3 was restored, but with the 7 rps controller. This provided good initial response, the delay time is the shortest of all cases so far, but a T48 limit violation slowed down the end of the transient back almost to the nominal level. Finally, in Case 6 the T48 limit was raised, allowing the largest $T 48$ excursion of all cases, but it also provided the fastest fan speed response from beginning to end. These cases point out the complexity of the interaction of limits within the controller. Clearly all limit modifications must be coordinated to achieve the fastest possible response, as demonstrated by Case 2, where the fast linear controller actually slows down the response when it hits the acceleration limit. It is also clear that without relaxing the $T 48$ limit, Cases 3 and 5 compete for best response, depending on the importance of delay time versus rise time; the common feature in these cases is the acceleration limit relaxation.

\section{Overspeed Control}

Overthrust can be used to avoid a collision, such as in the case of runway incursion, or to remain flying with wing damage, for instance. Maximum thrust corresponds to maximum fan speed, so for the C-MAPSS engine to achieve overthrust, the throttle must be allowed to move beyond its normal top setting of $100^{\circ}$. This may require that temperature, speed, and pressure limits be increased if the thrust requirement is very high. Analysis with the 
C-MAPSS engine shows that at sea level static, standard day conditions, most key engine variables vary essentially linearly with increased thrust demand up to 115 percent of maximum, and then nearly linearly up to 125 percent. The sensitivity of engine variables to TRA movement is shown in Table 6.

Although the final speed might need to be reached quickly, as in the case of runway incursion, overspeed is primarily a steady state type of operation. Therefore, the failure modes will tend to be creep and stress rupture, as well as other time-at-temperature and speed-related stress failures (Ref. 12). This is different from fast response control where thermal transient-related LCF is anticipated to be one of the primary failure modes (Ref. 12); however, operability is considered to be much more of a concern than structural integrity for fast engine response. Attempting to determine the increased risk due to enhanced operation is beyond the scope of this paper, but an example analysis (Ref. 20) is shown in Figure 8 for $\mathrm{L}_{10}$ disk life (the life at which 10 percent of parts will be expected to have failed). Here life is shown as a function of rotational speed, so an increase in speed can be related to a decrease in life at a 90 percent chance of survival using, for instance, Miner's rule (Ref. 21). Note that at sea level static, standard day conditions, the core speed at TRA of $100^{\circ}$ is about $9050 \mathrm{rpm}$, and at TRA of $125^{\circ}$ it is about 9300 .

TABLE 6. - CHANGE IN KEY VARIABLES WITH TRA FOR OVER-SPEED OPERATION, SLS STANDARD DAY

\begin{tabular}{|l|c|}
\hline \multicolumn{1}{|c|}{ Variable } & Change \\
\hline Fan speed, $N 1$ & $7.52 \mathrm{rpm} / \mathrm{deg}$ \\
\hline Core speed, $N 2$ & $10.12 \mathrm{rpm} / \mathrm{deg}$ \\
\hline EPR & $0.0041 / \mathrm{deg}$ \\
\hline$T 48$ & $6.24^{\circ} \mathrm{R} / \mathrm{deg}$ \\
\hline$P S 3$ & $3.76 \mathrm{psi} / \mathrm{deg}$ \\
\hline Thrust & $730 \mathrm{lbf} / \mathrm{deg}$ \\
\hline Fan stall margin & $-0.0276 \% / \mathrm{deg}$ \\
\hline LPC stall margin & $0.0444 \% / \mathrm{deg}$ \\
\hline HPC stall margin & $-0.0992 \% / \mathrm{deg}$ \\
\hline
\end{tabular}

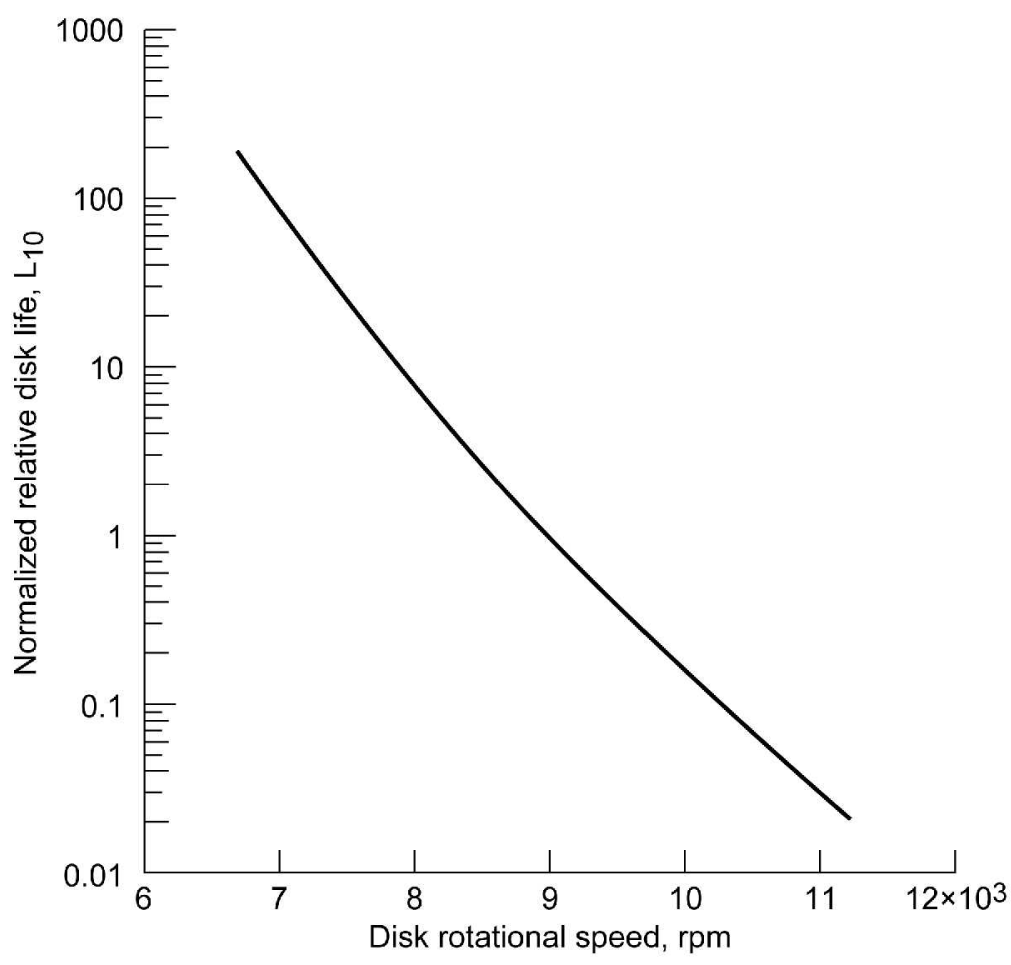

Figure 8.- $L_{10}$ disk life as a function of rotational speed based on Reference 20. 


\section{Discussion}

The examples using the C-MAPPS engine demonstrate that there is some ability to increase engine thrust response, specifically on acceleration. For a $5^{\circ}$ change in TRA (Table 4), the time to transition about 90 percent was more than halved, reducing the total by about $0.37 \mathrm{sec}$. Increasing the bandwidth of the controller clearly provides benefit for small throttle movements, but also helps speed up large throttle transients. However, in both cases increasing the fan speed controller's bandwidth had a negative effect if it was not modified in conjunction with other limits. The large throttle transient example involved the manipulation of acceleration limits as well as high limits, and yielded nearly half a second improvement in time to transition about 90 percent over the standard BOM control. The example clearly points out the complex interaction of the limits. This is compounded by the variations in performance around the flight envelope, additionally impacted by ambient conditions and deterioration. Deterioration also shifts uncontrolled variables, usually toward limits, reducing the benefit in manipulating limits because there is less margin available. There is a need to understand the total picture when changing limits to ensure that an improvement in response time will indeed result. This points out the need for an intelligent way to adapt limits, based on the conditions under which the engine is operating. It is clear that a thorough analysis of the kind shown here would need to be carried out at multiple points around the flight envelope. If the objective is to get the most performance out of the engine, information related to the engine's level of deterioration would need to be incorporated into an adaptive limit scheme as well.

For overspeed operation, the C-MAPSS engine's behavior is essentially linear with TRA. The high limits may have to be raised to accommodate the demand, which comes with a penalty in component life, but the risk analysis, at least for this given failure mode, appears to be straightforward.

\section{Conclusions}

It has been shown that an engine controller may be modified through redesign and the adaptation of limits to enable faster response and overthrust operation in emergency situations. However, this enhanced operation does not come without a price of decreased life and increased operability risk. In order to develop these emergency controllers, the engine's sensitivity to controller adjustments must be determined. Each type of engine has a controller designed specifically for it, with limits that take into account such things as material properties and component operability, so even though the results presented here may not be applicable to other engines, the methodology demonstrated would be the same.

This paper presents an example sensitivity analysis for the C-MAPSS engine and it points out the types of issues that must be addressed in the development of enhanced-operation controllers. Variations in performance due to operating point, ambient conditions, and deterioration were noted in the C-MAPSS engine. To understand if thrust response improvement is even possible, it must first be determined what the engine is capable of, and what part of the slow response is due to the controller. Only then, if the controller is determined to be unnecessarily conservative, can the effort to improve the response begin in a meaningful way. To develop a complete enhanced controller, it is essential to analyze the engine's performance to determine if there are optimal operating conditions, similar to previous throttles-only control work that suggested maintaining thrust well above idle. It may be that for a new or above average engine along with the knowledge of this fact, a modified controller will be able to eliminate a lot of the sluggishness at very low power. The controller schedule and limit adaptation procedure depends upon the level of deterioration of the engine and how the limits interact during transient operation. This will impact the ability to increase speed of response and thus must be understood in the context of the current operating scenario. It is not necessarily obvious or intuitive, as demonstrated by the examples. An intelligent approach to limit manipulation is required to achieve the best response.

Risk of operation also needs to be factored into any design, operability risk for fast response and risk of structural failure for overthrust and to a lesser extent for fast response. For the C-MAPSS controller, a key variable for improved response in a large throttle transient was the acceleration limit. Because the function of the acceleration limit is to prevent stall, knowledge of the deterioration level of the engine or the existing stall margin has the potential to greatly enhance the safety of incorporating adaptive controller limits for enhanced control modes for emergency operation. For overthrust operation, it was demonstrated that the expected component life will be significantly decreased by enhanced operation. This can be combined with existing knowledge of past use of the engine to determine an acceptable level of operational risk. Thus, if there is a reliable means to measure deterioration and life consumption, the thrust response of a good engine can be improved. The ability to improve the response time of deteriorated or below average engines is much more limited. 


\section{References}

1. National Transportation Safety Board, "Aircraft Accident Report, United Airlines Flight 232, McDonnell Douglas DC-1040, Sioux Gateway Airport, Sioux City, Iowa, July 19, 1989," PBSO-910406, NTSB/AAR$\mathrm{SO} / 06,1990$.

2. Tucker, T., "Touchdown: The Development of Propulsion Controlled Aircraft at NASA Dryden," Monographs in Aerospace History, Number 16, 1999, NASA History Office, Office of Policy and Plans, NASA Headquarters, Washington, DC 20546.

3. Burcham, F.W., Jr., and Fullerton, C.G., "Controlling Crippled Aircraft—With Throttles," NASA TM-104238, 1991.

4. Burcham, F.W., Jr., Fullerton, C.G., and Maine, T.A., "Manual Manipulation of Engine Throttles for Emergency Flight Control," NASA/TM-2004-212045, January 2004.

5. National Transportation Safety Board, "Aircraft Accident Report, Aloha Airlines Flight 243, Boeing 737-200, N73711, Near Maui, Hawaii, April 28, 1988," PB89-910404, NTSB/AAR-89/03, 1989.

6. National Transportation Safety Board, "NW Airlines, Inc., Flights 1482 and 299 Runway Incursion and Collision Detroit Metropolitan/Wayne County Airport Romulus, Michigan, December 3, 1990," NTSB/AAR91-05.

7. National Transportation Safety Board, "Aircraft Accident Report: Attempted Takeoff From Wrong Runway Comair Flight 5191 Bombardier CL-600-2B19, N431CA Lexington, Kentucky August 27, 2006," NTSB/AAR07/05, PB2007-910406, 2007.

8. Guo, T.-H., and Litt, J.S., "Resilient Propulsion Control Research for NASA Integrated Resilient Aircraft Project (IRAC)," AIAA-2007-2802, 2007 AIAA Infotech@Aerospace, NASA/TM-2007-214940, August 2007.

9. Guo, T.-H., Litt, J., Merrill, W., and Wood, B., "Fast-Response Engine Research: IRAC Propulsion Task," NASA Aviation Safety Technical Conference, 2008.

10. Litt, J.S. and Guo, T.-H., "Fast Thrust Response for Improved Flight/Engine Control under Emergency Conditions," ALAA Guidance, Navigation and Control Conference and Exhibit, 2008.

11. DeCastro, J.A., Litt, J.S., and Frederick, D.K., "A Modular Aero-Propulsion System Simulation of a Large Commercial Aircraft Engine," AIAA-2008-4579, 44th AIAA/ASME/SAE/ASEE Joint Propulsion Conference \& Exhibit, 2008.

12. Mattingly, J.D., Heiser, W.H., and Pratt, D.T., Aircraft Engine Design, 2nd ed., AIAA Education Series, AIAA, Reston, VA, 2002, pp. 663-677.

13. Spang, H.A., III, and Brown, H., "Control of Jet Engines," Control Engineering Practice 7, 1999, pp. 10431059.

14. Bonacuse, P.J., "Retirement for Cause as an Alternate Means of Managing Component Lives," Research \& Technology 1996, NASA/TM-107350, March 1997.

15. Sawyer, J.W., Gas Turbine Engineering Handbook, Gas Turbine Publications, 1966, p. 439.

16. Frederick, D.K., DeCastro, J.A., and Litt, J.S., "User's Guide for the Commercial Modular Aero-Propulsion System Simulation (C-MAPSS)," NASA/TM-2007-215026, October 2007.

17. Guo, T.-H., and Chen, P., "Sensor Based Engine Life Calculation-A Probabilistic Approach," ISABE-20031147, 16th International Symposium on Airbreathing Engines, 2003.

18. Roskam, J., Airplane Flight Dynamics and Automatic Flight Controls, Roskam Aviation and Engineering Corporation, 1979, pp. 1020, 1021.

19. Martucci, A., and Volponi, A.J., "Fuzzy Fuel Flow Selection Logic for a Real Time Embedded Full Authority Digital Engine Control," Journal of Engineering for Gas Turbines and Power, vol. 125, October 2003, pp. 909916.

20. Zaretsky, E.V., Smith, T., and August, R., "Effect of Design Variables, Temperature Gradients, and Speed of Life and Reliability of a Rotating Disk," NASA TM 88883, March 1987.

21. Melis, M.E., Zaretsky, E.V., and August, R., "Probabilistic Analysis of Aircraft Gas Turbine Disk Life and Reliability," Journal of Propulsion and Power, vol. 15, no. 5, September-October 1999, pp. 658-666. 


\begin{tabular}{|c|c|c|}
\hline \multicolumn{2}{|c|}{ REPORT DOCUMENTATION PAGE } & $\begin{array}{l}\text { Form Approved } \\
\text { OMB No. 0704-0188 }\end{array}$ \\
\hline \multicolumn{3}{|c|}{ 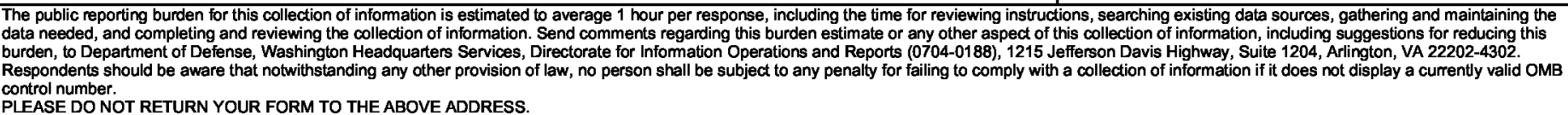 } \\
\hline $\begin{array}{l}\text { 1. REPORT DATE (DD-MM-YYYY) } \\
01-11-2009\end{array}$ & $\begin{array}{l}\text { 2. REPORT TYPE } \\
\text { Technical Memorandum }\end{array}$ & 3. DATES COVERED (From - To) \\
\hline \multirow{3}{*}{\multicolumn{2}{|c|}{$\begin{array}{l}\text { 4. TITLE AND SUBTITLE } \\
\text { The Case for Intelligent Propulsion Control for Fast Engine Respon }\end{array}$}} & 5a. CONTRACT NUMBER \\
\hline & & 5b. GRANT NUMBER \\
\hline & & 5c. PROGRAM ELEMENT NUMBER \\
\hline \multirow{3}{*}{\multicolumn{2}{|c|}{$\begin{array}{l}\text { 6. AUTHOR(S) } \\
\text { Litt, Jonathan, S.; Frederick, Dean, K.; Guo, Ten-Huei }\end{array}$}} & 5d. PROJECT NUMBER \\
\hline & & 5e. TASK NUMBER \\
\hline & & $\begin{array}{l}\text { 5f. WORK UNIT NUMBER } \\
\text { WBS 457280.02.07.03.04.03 }\end{array}$ \\
\hline \multicolumn{2}{|c|}{$\begin{array}{l}\text { 7. PERFORMING ORGANIZATION NAME(S) AND ADDRESS(ES) } \\
\text { National Aeronautics and Space Administration } \\
\text { John H. Glenn Research Center at Lewis Field } \\
\text { Cleveland, Ohio 44135-3191 }\end{array}$} & $\begin{array}{l}\text { 8. PERFORMING ORGANIZATION } \\
\text { REPORT NUMBER } \\
\text { E-17010 }\end{array}$ \\
\hline \multirow{2}{*}{\multicolumn{2}{|c|}{$\begin{array}{l}\text { 9. SPONSORING/MONITORING AGENCY NAME(S) AND ADDRESS(ES) } \\
\text { National Aeronautics and Space Administration } \\
\text { Washington, DC 20546-0001 }\end{array}$}} & $\begin{array}{l}\text { 10. SPONSORING/MONITOR'S } \\
\text { ACRONYM(S) } \\
\text { NASA; AIAA }\end{array}$ \\
\hline & & $\begin{array}{l}\text { 11. SPONSORING/MONITORING } \\
\text { REPORT NUMBER } \\
\text { NASA/TM-2009-215668; AIAA-2009- } \\
1876\end{array}$ \\
\hline \multicolumn{3}{|c|}{$\begin{array}{l}\text { 12. DISTRIBUTION/AVAILABILITY STATEMENT } \\
\text { Unclassified-Unlimited } \\
\text { Subject Categories: } 07 \text { and } 63 \\
\text { Available electronically at http://gltrs.grc.nasa.gov } \\
\text { This publication is available from the NASA Center for AeroSpace Information, 443-757-5802 }\end{array}$} \\
\hline
\end{tabular}

\section{SUPPLEMENTARY NOTES}

\section{ABSTRACT}

Damaged aircraft have occasionally had to rely solely on thrust to maneuver as a consequence of losing hydraulic power needed to operate flight control surfaces. The lack of successful landings in these cases inspired research into more effective methods of utilizing propulsiononly control. That research demonstrated that one of the major contributors to the difficulty in landing is the slow response of the engines as compared to using traditional flight control. To address this, research is being conducted into ways of making the engine more responsive under emergency conditions. This can be achieved by relaxing controller limits, adjusting schedules, and/or redesigning the regulators to increase bandwidth. Any of these methods can enable faster response at the potential expense of engine life and increased likelihood of stall. However, an example sensitivity analysis revealed a complex interaction of the limits and the difficulty in predicting the way to achieve the fastest response. The sensitivity analysis was performed on a realistic engine model, and demonstrated that significantly faster engine response can be achieved compared to standard Bill of Material control. However, the example indicates the need for an intelligent approach to controller limit adjustment in order for the potential to be fulfilled.

15. SUBJECT TERMS

Propulsion control; FADEC; Engine control

\begin{tabular}{|c|c|c|c|c|c|}
\hline \multicolumn{3}{|c|}{ 16. SECURITY CLASSIFICATION OF: } & \multirow{2}{*}{$\begin{array}{l}\text { 17. LIMITATION OF } \\
\text { ABSTRACT } \\
\text { UU }\end{array}$} & \multirow{2}{*}{$\begin{array}{l}\text { 18. NUMBER } \\
\text { OF } \\
\text { PAGES } \\
22\end{array}$} & \multirow{2}{*}{$\begin{array}{l}\text { 19a. NAME OF RESPONSIBLE PERSON } \\
\text { STI Help Desk (email:help@sti.nasa.gov) } \\
\text { 19b. TELEPHONE NUMBER (include area code) } \\
\text { 443-757-5802 }\end{array}$} \\
\hline $\begin{array}{l}\text { a. REPORT } \\
\text { U }\end{array}$ & $\begin{array}{l}\text { b. ABSTRACT } \\
\text { U }\end{array}$ & $\begin{array}{l}\text { c. THIS } \\
\text { PAGE } \\
\text { U }\end{array}$ & & & \\
\hline
\end{tabular}



